\title{
Study of Mass Spectra of Some Indole Derivatives
}

\author{
A. El Kihel1" ${ }^{*}$, M. Ahbala1, H. Sdassi' ${ }^{1}$, H. Ait Sir'1, A. Mouzdahir'1, P. Bauchat ${ }^{2}$ \\ ${ }^{1}$ Laboratoire de Chimie BioOrganique, Faculté des Sciences, El Jadida, Morocco \\ ${ }^{2}$ Ciblage et Auto-Assemblages Fonctionnels, UMR 6226, Université de Rennes I, Rennes Cédex, France \\ Email: *abdellatifelkihel@gmail.com
}

Received 7 March 2016; accepted 17 April 2016; published 20 April 2016

Copyright @ 2016 by authors and Scientific Research Publishing Inc.

This work is licensed under the Creative Commons Attribution International License (CC BY).

http://creativecommons.org/licenses/by/4.0/

c) (i) Open Access

\begin{abstract}
In the work, a study of mass fragmentation routes by the electron-impact mass spectrometry data has been examined for two open chain intermediates of indole derivatives and two pyrroloquinolines. By the isolation of open chain intermediate and the mass spectra, the structures of pyrroloquinoline have been confirmed.
\end{abstract}

\section{Keywords}

Indole, Open-Chain Intermediate, Pyrroloquinoline, Fragments

\section{Introduction}

Isolation of open-chain intermediates plays a key role in many synthetic organic reactions. Mass spectra data of the condensed indoles as pyrroloquinoline and the stability of the intermediates confirm the structure of the pyrroloquinolie product.

The indole ring is an important pharmocophore in modern drug discovery. Pyrroloquinoline quinone (PQQ) presenting the indole moeity, also known as methoxatin, was first identified in methylotrophic bacteria as a coenzyme for methanol dehydrogenase in 1979 [1]. It is widely distributed in a variety of food and other sources [2] [3], and is considered to be a redox active nutrient that can produce or scavenge superoxide depending on different cellular context [4]. In recent years, PQQ has garnered much attention due to its versatile roles in biological processes, including antioxidant function, cognitive promotion, neuroprotection and cardioprotection [5][7]. Also, PQQ is reported to have anticancer activity by inducing apoptosis in human Jurkat cells and promonocytic leukemia U937 cells, and this event is associated with generation of reactive oxygen species (ROS) [4] [8].

${ }^{*}$ Corresponding author. 
This report is concerned with the mass spectra of indole derivatives in order to confirm the structure of the obtained pyrroloquinolines.

\section{Experimental}

\section{MS Measurements}

The electron-impact mass spectra were recorded on Varian Mat 311 spectrometer at $70 \mathrm{eV}$ in the Centre de Mesures Physiques de l'Ouest (CRMPO) at Rennes 1 University. The electron ionization ion source was kept at $145^{\circ} \mathrm{C}$. The EI mass spectra were obtained over the range of $\mathrm{m} / \mathrm{z} 10-700$.

\section{Results and Discussion}

\subsection{Synthesis of the Studied Compounds}

The studied compounds were synthesized as shown in Scheme 1. Details of the synthetic methods are reported in our articles [9] [10]. Also, all the compounds were previously characterized by mass, ${ }^{1} \mathrm{H}$, and ${ }^{13} \mathrm{C}-\mathrm{NMR}$ spectra.

Scheme 1 shows the details of the synthetic methods that are reported in our articles [9] [10].

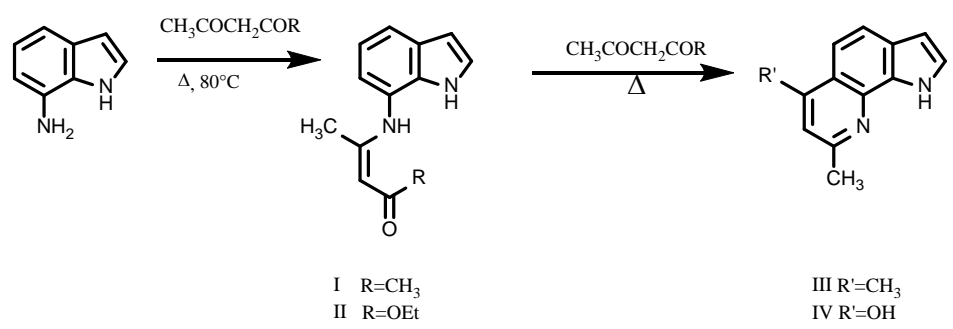

Scheme 1

\subsection{The Open Chain Intermediates I and II}

The composition of ions determined by exact mass measurements of these compounds are reported in Scheme 2 and Scheme 3.

In mass spectrometry, the presence of acetyl group is proved by ejection of one methyl radical from the molecular ion followed by the loss of one molecule of carbon monoxide. The loss of $\mathrm{CH}_{3} \mathrm{CN}$ then $\mathrm{HCN}$ fragments leads to the ions $\mathrm{m} / \mathrm{z}=116$ and 89 for $\mathbf{I}$. This fragment which eliminate one molecule of HCN leading to the ion $\mathrm{m} / \mathrm{z}=89$ is characteristic in indole fragmentation [11]. The cation $\mathrm{m} / \mathrm{z}=171$ for $\mathbf{I}$ was transformed to your tautomer then eliminate a methylene radical leading to the fragment $\mathrm{m} / \mathrm{z}=157 \mathrm{for} \mathbf{I}$.

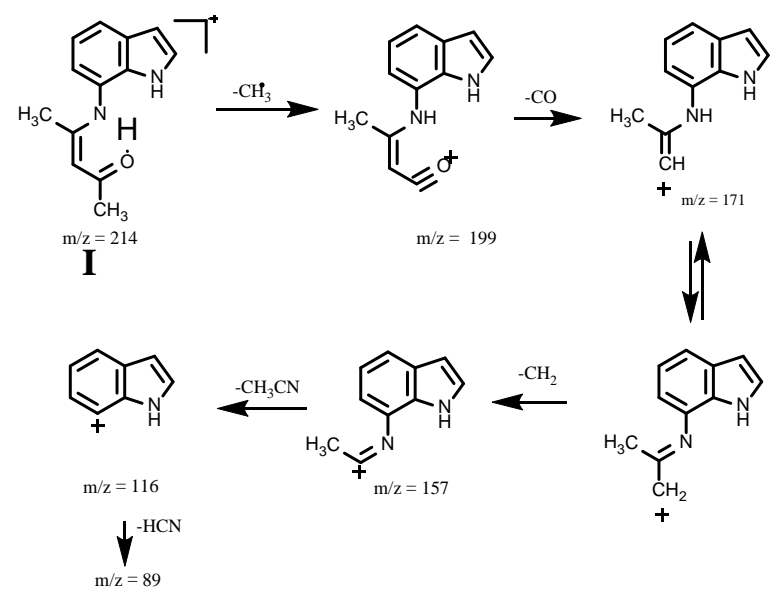

Scheme 2 
For the compound II, the presence of the function ester is deduced by splitting of a molecule of ethylene $\mathrm{C}_{2} \mathrm{H}_{4}$ following by ejection of one molecule of carbon dioxide giving the fragment $\mathrm{m} / \mathrm{z}=172$. The next fragmentations are similar to those of compound $\mathbf{I}$.

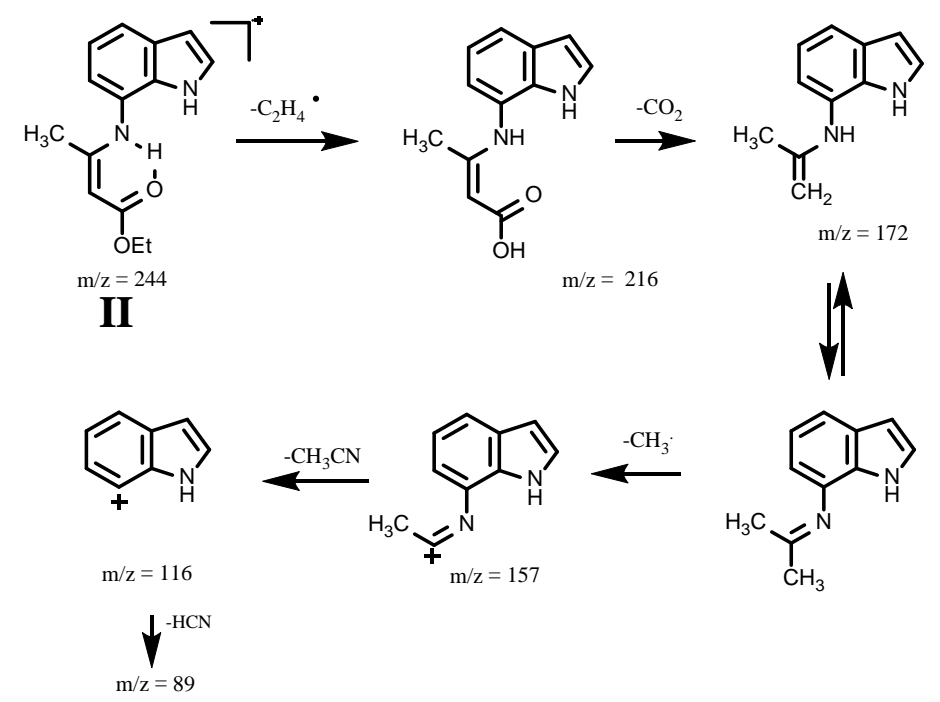

Scheme 3

\subsection{The Condensed Indoles: Pyrolloquinolines}

In the spectra of the compounds III and IV, the observed principal fragmentation processes are similar to those observed in open chain intermediate derivatives I and II.

The ions pyrrolobenzazépinium $\mathrm{m} / \mathrm{z}=195$ for III and $\mathrm{m} / \mathrm{z}=197$ for IV take place from the ejection of one radical hydrogen by the molecular ion which leading to the extension of the pyridinic nucleus characteristic of the aromatic ring bearing a methyl group. This data shows that the indolic proton is not concerned by the cyclisation of the open chain intermediate (Scheme 4 and Scheme 5).

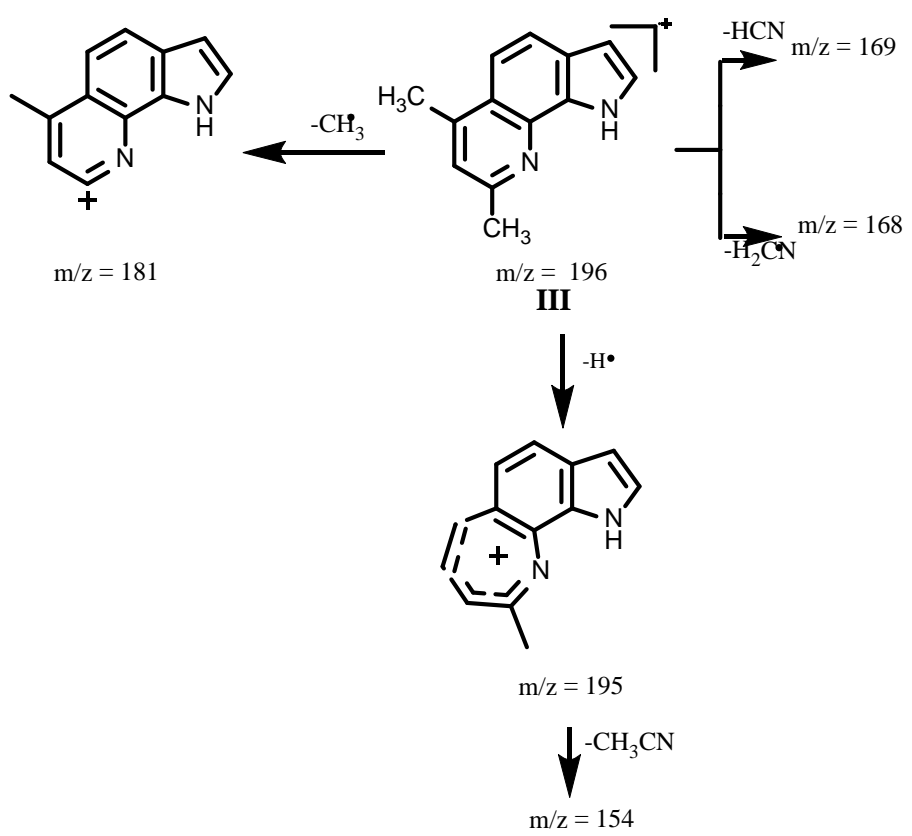

Scheme 4 


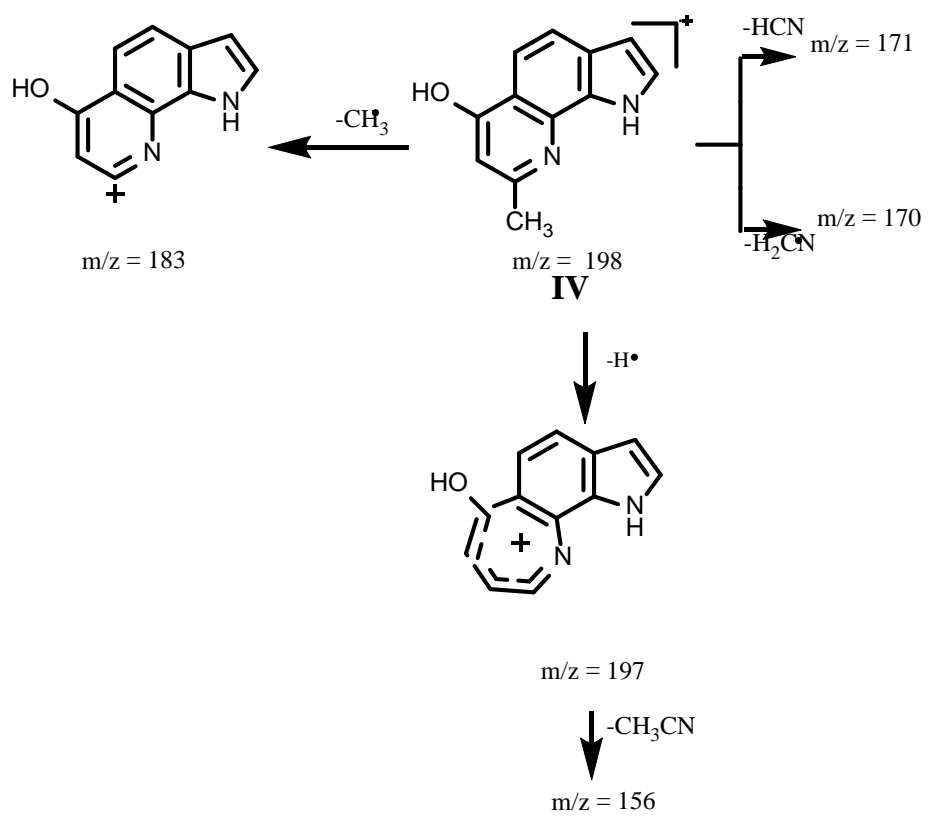

Scheme 5

\section{Conclusion}

In this work, mass fragmentation pathways of open chain intermediates of indole and pyrroloquinoline derivatives were investigated by electron impact mass spectrometry (EI-MS). The principal fragmentation processes in indole series are reported. The ion pyrrolobenzazépinium fragments were obtained from the extension of the pyridinic nucleus characteristic of the aromatic ring bearing a methyl group. These data show that the indolic proton is not concerned by the cyclisation of the open chain intermediate.

\section{References}

[1] Salisbury, S.A., Forrest, H.S., Cruse, W.B. and Kennard, O. (1979) A Novel Coenzyme from Bacterial Primary Alcohol Dehydrogenases. Nature, 280, 843-844. http://dx.doi.org/10.1038/280843a0

[2] Kumazawa, T., Seno, H., Urakami, T., Matsumoto, T. and Suzuki, O. (1992) Trace Levels of Pyrrolo-Quinoline Quinone in Human and Rat Samples Detected by Gas Chromatography/Mass Spectrometry. Biochimica et Biophysica Acta, 1156, 62-66. http://dx.doi.org/10.1016/0304-4165(92)90096-D

[3] Kumazawa, T., Sato, K., Seno, H., Ishii, A. and Suzuki, O. (1995) Levels of Pyrroloquinoline Quinone in Various Foods. Biochemical Journal, 307, 331-333. http://dx.doi.org/10.1042/bj3070331

[4] He, K., Nukada, H., Urakami, T. and Murphy, M.P. (2003) Antioxidant and Pro-Oxidant Properties of Pyrroloquinoline Quinone (PQQ): Implications for Its Function in Biological Systems. Biochemical Pharmacology, 65, 67-74. http://dx.doi.org/10.1016/S0006-2952(02)01453-3

[5] Stites, T.E., Mitchell, A.E. and Rucker, R.B. (2000) Physiological Importance of Quinoenzymes and the O-Quinone Family of Cofactors. Journal of Nutrition, 130, 719-727.

[6] Misra, H.S., Rajpurohit, Y.S. and Khairnar, N.P. (2012) Pyrroloquinoline-Quinone and Its Bversatile Roles in Biological Processes. Journal of Biosciences, 37, 313-325. http://dx.doi.org/10.1007/s12038-012-9195-5

[7] Rucker, R., Chowanadisai, W. and Nakano, M. (2009) Potential Physiological Importance of Pyrrolo-Quinoline Quinine. Alternative Medicine Review, 14, 268-277.

[8] Shankar, B.S., Pandey, R., Amin, P., Misra, H.S. and Sainis, K.B. (2010) Role of Glutathione in Augmenting the Anticancer Activity of Pyrroloquinoline Quinone (PQQ). Redox Report, 15, 146-154. http://dx.doi.org/10.1179/174329210X12650506623762

[9] El Kihel, A., Ahbala, M., Harjane, T., Essassi, E.M. and Bauchat, P. (2007) Condensation des 7-aminoindoles avec l'acetoacetate d'ethyle. Physical and Chemical News, 34, 85.

[10] El Ouar, M., Knouzi, N., El Kihel, A., Essassi, E.M., Benchidmi, M., Hamelin, J., Carrié, R. and Danion-Bougot, R. 
(1995) Reactivity of 7-Aminoindoles with Acetylacetone. Synthetic Communications, 25, 1601. http://dx.doi.org/10.1080/00397919508015844

[11] Vul'fson, N.S., Zaretskii, V.I., Kisin, A.V. and Suvorov, N.N. (1957) Study of Modes of Fragmentation of Formyl- and Carbalkoxyindoles. Khimiya Geterotsiklicheskikh Soedinenii, 3, 502. 